\title{
NEW PARADIGMS AND NEW CHALLENGES
}

\author{
Paul K. Davis \\ The RAND Corporation and \\ The RAND Pardee Graduate School \\ 1776 Main St. \\ Santa Monica, CA 90407-2138, U.S.A.
}

\begin{abstract}
This paper lays out provocative assertions about major challenges for the modeling and simulation community. One relates to building M\&S for the purpose of assisting the search for strategies that are flexible, adaptive, and robust despite uncertainty. A key aspect of this search is exploratory analysis, coupled with selective zoom. These, in turn, require multiresolution modeling with sound models (albeit, with uncertain data). But sound models must be adaptive models, since humans are adaptive. And rigorous analysis with adaptive models, such as those involving agents, requires new methods and attitudes, as well as new tools.
\end{abstract}

\section{INTRODUCTION}

This paper is organized around the following propositions, discussed in turn:

1. Because of ubiquitous and often massive uncertainties, analysis should often discard notions of "optimizing" and instead focus on finding strategies that are flexible, adaptive, and robust. This goes beyond the heuristic of finding a strategy that is "good enough."

2. Doing so is best accomplished with a combination of exploratory analysis and selective zooming using sound, mutually informed families of models, games, and other sources of information.

3. The soundness of models often depends of incorporating adaptiveness (e.g., through one or another type of agent).

4. Rigorous analysis with adaptive models requires a new set of attitudes and methods.

Those who build models, simulations, and related analysis tools can do much to help. They can:
- Design for multiresolution, multiperspective work and for use of diverse sources of information.

- Build tools to facilitate context-dependent aggregation, disaggregation, and calibration.

- Build in adaptiveness and related explanation capabilities.

Some of the ideas expressed here have evolved from my work over the last two decades. Others are new and less well formed.

\section{PROPOSITIONS FOR AN UPDATED APPROACH}

\subsection{Demoting the Paradigm of Optimizaton}

The shortcomings of focusing on optimization have been noted for the last fifty years. In the 1950s and 1960s, for example, the late Nobelist Herbert Simon introduced his concept of bounded rationality, which elaborated the fact that in real-world strategic decision making it is not possible to apply the idealized notion of maximizing expected subjective utility because so many of the key inputs to such a calculation are uncertain, even deeply so. He went on to suggest that the best we can do is to satisfice, i.e., find a strategy that is "good enough," and that the way real people accomplish that often involves heuristics of various types.

Simon's work dovetailed with some of the discoveries of behavioral psychologists, notably Nobelist Daniel Kahneman and Amos Tversky, who observed in the laboratory that real people use a wide variety of heuristics when making decisions. The early thrust of the Kahneman-Tversky work tended to emphasize that the heuristics sometimes led to "cognitive biases" and to decisions that are irrational as judged by the standards of classic utility-maximizing decision theory. Numerous researchers proceeded to seek ways of correcting for these "errors" and attempts have been made to introduce debiasing mechanisms in decision support systems. 
Over the last decade or so, it has become increasingly evident, however, that not only do real humans tend to make decisions in very different ways than envisioned by the so-called rational analysis paradigm, so also are there virtues in doing so. First, the "naturalistic" methods suit biologically wired-in mental processes; second, they also hedge well for the real world in which facts are very seldom so cut-and-dried as asserted in the psychology tests that demonstrate the allegedly irrational heuristics at work.

A synthesis in decision making theory should recognize the virtues of both the rational-analysis approach and the naturalistic approach studied by Gary Klein, Gird Gigerenzer, and others, and do so with special appreciation that real-world decision-support should account realistically for uncertainty. Much of this is discussed in a recent survey (Davis, Kulick, and Egner 2005), which cites the relevant literature, particularly articles by Simon, Kahneman and Tversky, Klein, and Gigerenzer.

Progress has also been made in the theory and practice of confronting uncertainty in applied work (Davis, 1993, Davis, 2002). Most recently, the Department of Defense has accepted the need for this, shifting to capabilitiesbased planning (CBP) precisely because of the appreciation by Secretary of Defense Rumsfeld that planning built around long strings of highly uncertain assumptions makes no sense. The emphasis, instead, should be on strategies and plans that are flexible, adaptive, and robust. It is doubtful that Secretary Rumsfeld has ever asked one of his generals or staff members whether a higher-level strategy was "optimal." $\mathrm{He}$ has repeatedly asked, however, whether uncertainties have been adequately considered. This new emphasis is by no means idiosyncratic to Rumsfeld. Indeed, secretaries of defense have usually thought in CBP-like terms, even while their organizations have acted to obfuscate uncertainty and create convenient myths and routines, such as focusing on plans for two highly specified more-or-less-simultaneous major theater wars.

To be sure, optimization is still profoundly important for many problems of operations research and daily life. The paradigm shift is recognizing that the style and implicit assumptions associated with optimization are often fundamentally wrong-headed when dealing with more strategic matters, or indeed any matters where uncertainty is large, deep, and ubiquitous. Table 1 draws some contrasts, albeit with some exaggeration.

\subsection{Finding Adatpive Strategies}

For the remainder of the paper I will shorten the phrase "flexible, adaptive, and robust" to "adaptive." How do we find a good adaptive strategy?

It is apparent that to do so we need some mechanism for evaluating the possible outcome of a given strategy over a wide range of assumptions - not just one or two mathematically convenient parameters, but over all of the
Table 1: Contrasts of Paradigm

\begin{tabular}{|l|l|l|}
\hline Issue & $\begin{array}{l}\text { Stereotypical Opti- } \\
\text { mizer's Attitude }\end{array}$ & $\begin{array}{l}\text { Strategist's Atti- } \\
\text { tude }\end{array}$ \\
\hline Uncertainty & $\begin{array}{l}\text { Look for "authorita- } \\
\text { tive data" (whether or } \\
\text { not valid) }\end{array}$ & $\begin{array}{l}\text { Confront uncer- } \\
\text { tainty so as to in- } \\
\text { crease odds }\end{array}$ \\
\hline $\begin{array}{l}\text { Objective } \\
\text { of Analysis }\end{array}$ & $\begin{array}{l}\text { Optimal strategy (for } \\
\text { narrow set of as- } \\
\text { sumptions) }\end{array}$ & $\begin{array}{l}\text { Flexible, adaptive, } \\
\text { and robust strategy }\end{array}$ \\
\hline Precision & To be sought & Noninterest \\
\hline Utility & $\begin{array}{l}\text { An essential concept } \\
\text { for optimization }\end{array}$ & $\begin{array}{l}\text { Contempt, because } \\
\text { of multiple objec- } \\
\text { tives that are not } \\
\text { usefully combined }\end{array}$ \\
\hline
\end{tabular}

uncertainties that matter. Furthermore, we need to be able to reason about the analysis. We don't want to make important decisions based on some numbers that came out of a huge model; instead, we want to be able to reason along the lines, "Hmm, it seems that with Option 1 we do well for most reasonable values of $\mathrm{X}$ and $\mathrm{Y}$, but we fall apart if Z's value is low, which is plausible. Option 2, on the other hand, does almost as well across reasonable values of $X$ and $\mathrm{Y}$, but also does much better across all values of $\mathrm{Z}$. Option 2 is better."

Realistically, our reasoning must revolve around a small number of variables - two, three, or a dozen, but not tens, hundreds or thousands. That implies the need for a low-resolution model of the problem. However, such an abstracted depiction hides many important matters. Thus, being able to explore the consequences of an option across the broad range of uncertainties at low resolution is necessary, but not sufficient. We also need to be able to zoom into more detail, both to understand the implications of our high-level reasoning (what are we implicitly assuming about more microscopic factors?) and to move from grandiose strategy to matters more concrete. Just as a designer uses a low-resolution model to sketch his system, but needs more detailed models to define it usefully and well, so also should strategic decision making be supported by both low- and high-resolution depictions. Table 2 contrasts the value of low and high-resolution models, simplifying as though there were only two levels and types of resolution (Davis and Bigelow 1998 and earlier references).

An additional complication is that, whether in exploring at low resolution or seeking to zoom for more information, it often happens that we need to think about problems "differently," i.e., with different variables. If a military commander shifts his attention to logistics, for example, he may find himself having to reason in a different framework, and with different variables, than when talking to those focused on strike or maneuver. An even better example perhaps is when an acquisition executive consults both bottom-up engineering models and empirical cost models when assessing what to expect for a next-generation system. 
Table 2: Value of Low and High-Resolution Models

\begin{tabular}{|l|l|}
\hline \multicolumn{1}{|c|}{ Low-Resolution } & \multicolumn{1}{c|}{ High-Resolution } \\
\hline Early design & Detailed design \\
\hline $\begin{array}{l}\text { Using low-resolution } \\
\text { knowledge }\end{array}$ & $\begin{array}{l}\text { Using high-resolution } \\
\text { knowledge }\end{array}$ \\
\hline $\begin{array}{l}\text { Analysis responding to } \\
\text { high-level questions }\end{array}$ & $\begin{array}{l}\text { Narrow, in-depth analysis } \\
\text { for accuracy, precision, or } \\
\text { detail }\end{array}$ \\
\hline $\begin{array}{l}\text { Reasoning and comprehen- } \\
\text { sion with high-level vari- } \\
\text { ables }\end{array}$ & $\begin{array}{l}\text { Reasoning and comprehen- } \\
\text { sion in terms of more } \\
\text { atomic phenomena }\end{array}$ \\
\hline $\begin{array}{l}\text { Informing, calibrating, or } \\
\text { summarizing high- } \\
\text { resolution work }\end{array}$ & $\begin{array}{l}\text { Informing, calibrating, or } \\
\text { explaining low-resolution } \\
\text { work }\end{array}$ \\
\hline Abstracting “big picture" & Simulating reality \\
\hline
\end{tabular}

The result of such considerations is that we need multiresolution, multiperspective families of models (FOMs). Actually, even more is needed, since some of the models that may be important are naturally expressed in different formalisms (e.g., differential equations versus expert systems versus closed-form analytical expressions). Ideally, we should have families and the ability to navigate among family members even while accomplishing necessary changes of representation and formalism. (Davis 2002, Dreyer and Davis 2005, Davis, Kulick, and Egner 2005).

Even this is not enough. Models, after all, depend on input data and their structure depends on beliefs about the world. Where do we get the necessary information? It may be common for those involved with $M \& S$ to stick closely to their computer programs and officially distributed data bases, but real information comes in diverse forms and is often contradictory. If our search for a robust adaptive strategy is to be successful, we may need to draw on all of the information available. How do we do so?

One answer has been the image that organizations often offer, which involves a putative family of models arranged in a pyramid, with the models all calibrated bottomup, thereby allowing the organization to claim that each of its models is rock-solidly based in a deeper model and, ultimately, in reality. Perhaps that would be a useful image if the models and data were perfect, but that, of course, has nothing to do with reality.

A wiser course is to recognize that to do a first-rate job we should use fragments of knowledge from many sources - in different resolutions, perspectives, and formalisms. Our ideal should be something like Figure 1 (National Research Council 1997), which emphasizes mutually informed and calibrated models that make use of everything from historical accounts (sometimes called anecdotes) to hard laboratory or field-test data to theory. There is nothing cut-and-dried about such an image. Lest this seem unexceptionable, the reader may ask how often he has used more than one or two of the types of data on the left side. In my experience, it is a rare individual who does so.

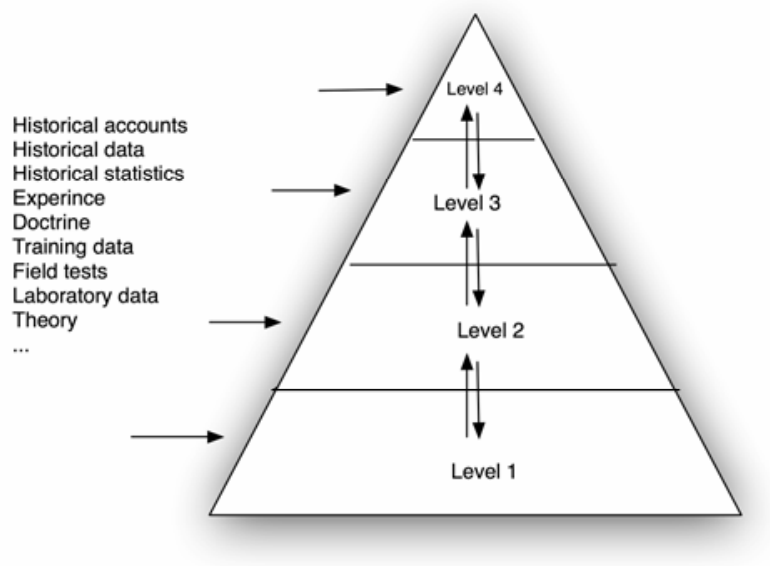

Figure 1: Mutual Calibration and Diverse Information

It is, moreover, nontrivial to move among such sources of information. Currently, for example, my colleagues and I are building models to inform counterterrorism efforts. We are drawing on the empirical socialscience literature. That literature, however, tends to generate regression data on whether, over the last $\mathrm{n}$ years, increased levels of development or democratization have tended to be correlated with increased or decreased levels of terrorism. The results are complicated by the heterogeneity of the data base and related hidden variables. For example, civil wars may have occurred, which focused the energy of revolutionaries on something other than terrorism. Or perhaps the issue was less democratization than the loss of state control over seditious political activities. In any case, the studies are very useful in informing simulations, but not in calibrating them. Similarly, highly aggregate data on historical battles is often not straightforward to use when calibrating simulation models of combat. Nonetheless, there is information to be gleaned and time invested can be worthwhile - especially if it is time spent on understanding phenomena rather than just generating statistics. As an example, it took years before researchers doing regression analysis on historical attrition data, trying to fit it to one or another Lanchester equation, finally came to the reluctant conclusion that the battles in question had phases with different characteristics. In a good simulation model, by contrast, that is obvious: the type battle and type terrain are state variables that change at each time step. There may, for example, be an assault phase and a very different post-breakthrough phase. The notion of constant attrition coefficients, as in Lanchester equations, can be grossly nonphysical. So also can static regression equations.

On the one hand, then, we should milk all the forms of information available. On the other hand, we should not attempt to do so naively. Indeed, a good deal of modeling may be necessary to relate empirical information to the parameters of a simulation model. 
Table 3 provides an image for thinking about how different sources of information can assist in different ways. Every time I rethink the issue, the image changes a bit, because of various subtleties, but the basic idea is simple: simple, low-resolution analytical models (top left) are great for agility and breadth (covering the landscape), but poor for unveiling phenomenology, especially human behavior. In contrast, field exercises (lower right) are reasonably good for unveiling phenomenology and especially good for revealing certain aspects of human behavior, but are poor with respect to agility and breadth. A theater-level simulation (referred to as a strategic simulation in the table) could be rather good for agility, breadth, and even phenomena, including human phenomena-but only if it included realistic adaptation mechanisms, such as from relatively sophisticated agents, as discussed in the next section. Without such mechanisms, however, it would be much weaker. Table 3 includes lines for both analysis of historical data and paying attention to historical anecdotes and other accounts.

Table 3: Comparing Strengths and Weaknesses of Diverse Information Classes

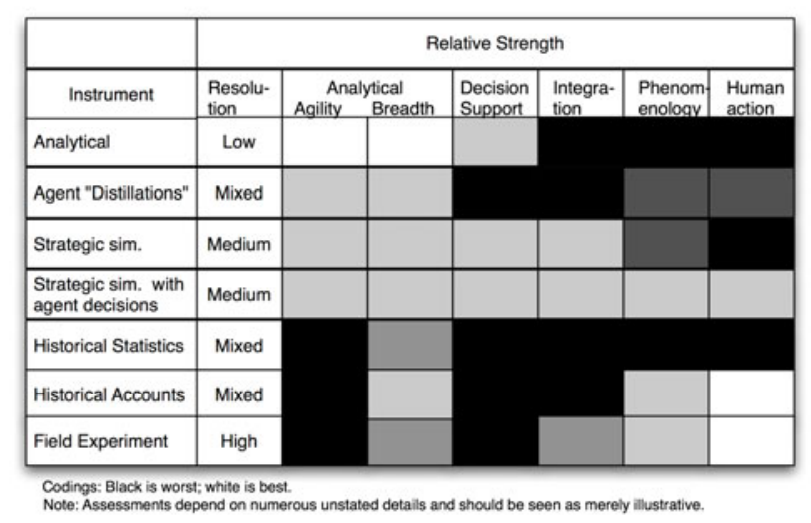

\subsection{Achieving Adaptiveness with Agents and Other Mechanisms}

If the models and other information sources of our imagined family are to be truly good, in the sense of being able to predict outcomes reasonably given a set of inputs (albeit uncertain ones), then we must recognize that the systems of interest in combat modeling are typically complex-adaptive systems (CAS). This implies the need to represent human behaviors and decisions dynamically. In some instances that can be accomplished with submodels built in the style of a control theorist, or game theorist, but in many instances it is more appropriate to use one or another version of what are called "agents."

I understand, of course, that clever analysts can often make do with scripted models, and that scripted models vary a great deal in their rigidity. If behaviors are sensitive to the right dynamic state variables, perhaps including some state variables representing limited memory, then observed behaviors can sometimes be realistic enough to pass muster. For example, it doesn't require agent-based modeling to have a simulated aircraft veer before running into a mountain, or for a simulated sensor detect a weak but repetitive signal.

The fact remains, however, that most of our legacy models and some of our newer ones are too rigid in important respects, and that analysts are fooling themselves if they believe that they can easily make do by merely rerunning the simulation and tuning parameters until the behavior seems reasonable. That tuning may often be excessively dependent on the detailed situation. If some parameter of the simulation is changed slightly, the scripted behavior may no longer be appropriate, thereby undercutting the validity of sensitivity analysis and creating mysterious nonmonotonicities. More adaptation is needed in the models.

As a facetious example of what is involved, suppose that we have a model of what happens when a dim-witted individual piles head-on, repeatedly, into a block of variable hardness. We might ask how long it takes for the dimwit to kill himself, as a function of the block's hardness. Perhaps the answer is the dark curve in Figure 2. However, if we considered the simplest possible adaptive behavior (a super-simple agent), the result might be as shown by the dashed line: adding more hardness does no cause earlier death, but rather, after a slam or two, even the dim-wit backs off. If this sounds irrelevant, consider classic piston models of ground-force attrition. No matter how unwise it would be in the real world to continue fighting, the losing side grinds away until it disintegrates. A real general would more likely pull back to fight another day. The model could readily be designed to permit a periodic decision on such matters, but older models typically treat strategy as a fixed input buried in data.

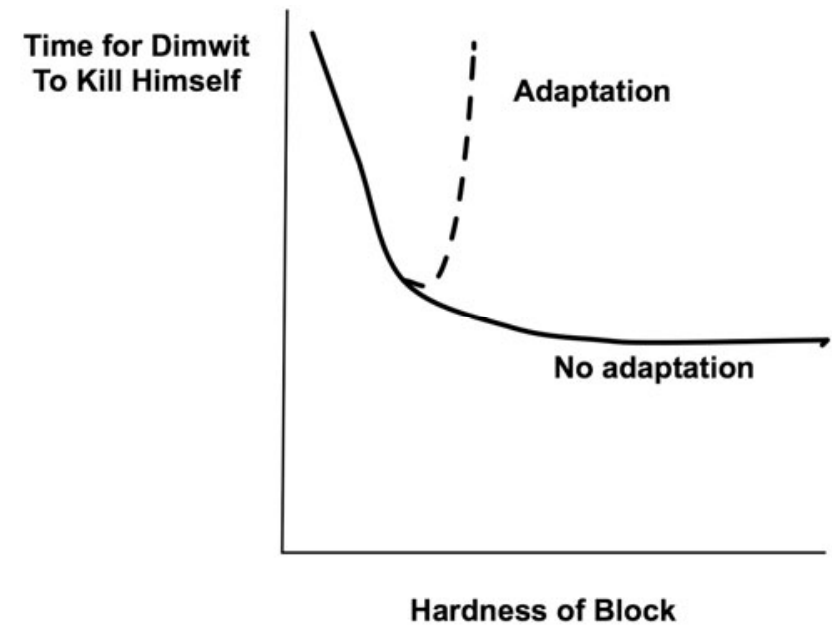

Figure 2: Implications of Adaptation 
As another example, consider a serious study some years back in which two competing models described how the number of enemy aircraft killed in a campaign depended on the number of U.S. Patriot batteries deployed. The first model showed a monotonic increase. In contrast, the second model showed a drop in aircraft killed as the number of Patriots increased. Why? The reason was that in the second model the adversary's strategy for use of air forces was adaptive: when U.S. sectors were well protected, the attacker focused instead on allied sectors. In this instance, the adaptation was due to a game-theoretic decision model (SAGE) developed by colleague Richard Hillestad (unpublished). Functionally, it was behaving like an agent.

What does it take to introduce such modest approximations of realism? Essentially, it requires that the sides' reassess their strategy and tactics from time to time and that they have alternative courses to take. One way to accomplish that is with agents.

In theory there are many possible agents types with very different logic and programming styles. A number of authors have offered definitions of "agent," but I am most struck by how different (and parochial) the definitions often are. An excellent comparison of definitions, followed by a useful taxonomy is given by Franklin and Graesser (1998).

Informally, it seems to me that the elementary concept of agent is and should be of "an object that acts in behalf of," with "object" being either simply a chunk of code or an object in the sense of object-oriented modeling. For example, even older theater-level combat models sometimes had simple algorithms that operated at regular intervals to allocate operational ground-force reserves among sectors. Such algorithms were arguably acting as simple agents in the sense of acting in lieu of the humans who would otherwise have made decisions interactively. The game-theoretic SAGE model mentioned earlier acted as a theater air commander. Nonetheless, neither of these was regarded at the time as an agent. Some would argue that "algorithmic" approaches are not in the spirit of agent-ness, but that strikes me as some kind of technologist's bias. It reminds me of when, in the 1980s, some people looked down upon expert-system-type artificial-intelligence systems unless they were built in LISP, even when some of us discovered that a model built originally in a LISP-based language could be made 1000 times faster and in some ways clearer by reprogramming into a more efficient language, typically procedural.

\subsection{Alternative Mechanisms for Adaptiveness}

Let me now describe briefly at least a few very different ways of achieving adaptive behavior in military models.

\subsubsection{The RAND Strategy Assessment System (RSAS): Complex Agents in a Complex Simulation}

The RAND Strategy Assessment System reached fruition just in time (circa 1988) to see the Soviet Union go belly- up. It had adaptive logic from the perspective of a theater commander. Its inputs could include theater objectives, alternative strategies, tradeoff rules if tradeoffs had to be made, and various metrics for assessing how well a given strategy was working or was likely to work. In the RSAS, these included a stored library of results from past simulations. Looking at a few current state variables, and some history such as how much mobilization time the sides had had before war began, the agent could look at its library of past simulations and see that prospects were, say, very good, good, marginal, bad, or very bad. The result might cause the agent to change strategies or keep plodding. Alternatively (but not so usefully in practice), the decision model could order up a "look ahead" in which the simulation would be run "inside itself" to assess alternative strategies before the best one was chosen.

These models were called Red and Blue militarycommand-level agents, and were motivated in part by the artificial-intelligence method known as slotted scripts, but mostly by the real-world image of war plans with branches and sequels (Schwabe 1992).

An even higher-level set of agents represented the national-command levels of Red (Soviet Union and Warsaw Pact) and Blue (United States and NATO). These agents were less plan-bound and more focused on objectives, strategies, and, within that, issues of escalation, deescalation, and termination (Davis, Bankes, and Kahan 1986). A composite Green Agent represent third countries, which had to decide with whom to cooperate, and to what degree. They could base this on allegiances, bandwagoning, narrow self interest, and other considerations (Shlapak 1988).

None of the Red, Blue, and Green agents had much in common with the agent-based models in common use today. They certainly acted in behalf of humans (and could be replaced by humans at decision points), sensed the environment, communicated, directed resources, and learned (in a limited sense). They could also change in the sense that we did simulations that included replacement of one Red Agent by another, representing a coup. The agents did not, however, include random actions, mutation in the usual sense, or general AI-style learning. Furthermore, despite experiments with AI-style programming, we chose to build the agents top-down with well-defined, hierarchical logical rules. Thus, they were quite different from the LISP or PROLOG-style agents of the era.

\subsubsection{Current-Day Relatively Simple Agents in Simple or Moderately Simple Simulations}

Another way to achieve adaptation is with the kind of agent-based modeling that many authors currently have in mind when they use that term. A number of recent references provide background (Sanchez and Lucas 2002, Hill, Champagne, and Price 2004, Horne and Johnson 2002), 
citing the seminal efforts of Andrew Ilachinski's ISAAC (Ilachinski 2000).

The current tendency is to equate agent-based modeling with models that have simple or only moderately complex simulation, plus agents characterized by simple behavior rules informed by observation of the environment. The behaviors are often stochastic. Some of the simpler agent-models are called distillations because the intention is to distil the essence of complex behavior.

Interestingly, some of those using these agent-based models have done so out of frustration with official legacy models with which they are to some extent stuck. Unfortunately, these models are sometimes puzzling because, while they may exhibit interesting and plausible behaviors, the behaviors are often difficult to understand. The simulations in which the agents are embedded have uncertain validity, and the interaction of the agents with the simulations sometimes seems contrived or over-aggregated (a criticism also of pioneering applications in social systems, such as Epstein and Axtell 1996). In other cases, the simple agents and simple simulations seem clearly to provide a good deal of legitimate insight, even to those not easily convinced.

\subsubsection{A Contrasting Type of Current Agent-Based Modeling}

As a contrasting example of current-day work, consider next the Systems Evaluation Analysis Simulation (see Zinn 2004 or http://www.teamseas.com/).

SEAS was developed at Aerospace Corp. by Robert Weber and others, later with assistance from RAND and with support from Sparta. One of its important purposes is to illuminate the value of space and C4IS4 systems as a function of related architectures, context, and concepts of operation. It was designed from the outset for exploratory analysis in the information domain.

SEAS is a rather complex simulation with relatively complex agents. It was designed by analysts with studies in mind. As a result, analysis is more nearly straightforward and less dependent on the complex statistical analysis described, for example, in Sanchez and Lucas (2002). Even so, interpretation can be challenging.

\subsubsection{The Range of Adaptation Types}

The point of this background is that we need adaptation in models, but that there are many ways to achieve it, with greater or lesser sophistication, and the adaptivity can be coupled to a simple or complex simulation. We can find examples of all of these if we look. Table 4 gives one such list. Columns differ by the complexity of the adaptation mechanism; rows differ by the complexity of the simulation.
Table 4: Examples of Model Types

\begin{tabular}{|l|l|l|l|}
\hline $\begin{array}{c}\text { Adaptation } \\
\text { Mechanism } \\
\text { Simulation }\end{array}$ & None & Simple & Complex \\
\hline Simple & $\begin{array}{l}\text { Lanchester } \\
\text { equations }\end{array}$ & ISAAC & $?$ \\
\hline Moderate & $\begin{array}{l}\text { Most } \\
\text { spreadsheet } \\
\text { models }\end{array}$ & $\begin{array}{l}\text { MANA, } \\
\text { EXHALT }\end{array}$ & SEAS \\
\hline Complex & $\begin{array}{l}\text { Janus, } \\
\text { most thea- } \\
\text { ter models }\end{array}$ & $\begin{array}{l}\text { JICM with } \\
\text { some adap- } \\
\text { tive logic }\end{array}$ & $\begin{array}{l}\text { Brawler, } \\
\text { SAGE, } \\
\text { RSAS, } \\
\text { Eagle, } \\
\text { NSS, One- } \\
\text { SAF }\end{array}$ \\
\hline
\end{tabular}

Table 4 characterizes the overall model by whether the simulation (e.g., the physics) is simple, moderate, or complex, and by whether the model has no adaptation, simple adaptations, or complex adaptations. Lanchester-equation simulations are simple and have no mechanism for adaptation. As with the dimwit above, the losing side continues fighting until eradicated. The early work by Ilachinski with ISAAC had a very simple simulation for movement and terrain, but also included simple agents. The result was interesting and surprisingly realistic tactics by the simulated Marine infantry. I am not sure of a good example of a simple simulation and complex agents, but there surely are some. Turning to the second row, consider that most of the spreadsheet-level models that many of us build have no adaptation mechanisms. However simple agents can be built. The EXHALT model (McEver, Davis, and Bigelow 2000) includes an agent representing a commander trading off the depth of enemy advance at which he can expect to halt an invasion against the losses of his own aircraft and pilots. That "agent" was built without the benefit of the convenient structures available in agentbased programming languages. In contrast, models built with MANA (Lauren, Stephen, and Anderson 2002) employ an easily used mechanism for building agents and the simulations are also simple or only moderately complex. The SEAS model mentioned earlier has a moderately complex or complex simulation of space and C4ISR, and moderately sophisticated agents at several levels of detail. Turning to the last row, Janus is an excellent example of a complex simulation (developed originally by Donald Blumenthal and colleagues at Lawrence Livermore National Laboratory) with no adaptive behaviors. RAND's JICM (Joint Integrated Contingency Model) is a global- and theater-level model that has, e.g., some simple low-level algorithmic agents (e.g., one that decides which sectors to reinforce) and that can be given higher-level adaptive logic, although not all users bother to do so. Brawler is the Air Force's venerable engagement-level model of air-to-air warfare in which mathematician-style algorithms are used 
to create behaviors that pass muster when viewed by pilots; SAGE is an undocumented game-theoretic optimizer of air-force allocations and apportionments in a theater-level model; as mentioned above, the RSAS of the 1980s had sophisticated agents representing U.S. and Soviet leaders, and NATO and Warsaw Pact theater commanders. Eagle, developed for the Army by the Los Alamos National Laboratory and the MITRE Corporation for corps-level combat, used expert-system agents for adaptations. One-SAF is the Army's next-generation entity-level brigade-and-below constructive simulation. It will incorporate a number of approved behaviors in entity-level simulation (see www. onesaf . org).

The point, then, is that building in adaptiveneess can be done with any of a number of approaches.

\subsection{Achieving Rigor with Agent-Based Models}

One of the obstacles in using adaptive models, and particularly agent-models, has been a set of long-standing attitudes about what is required from models for rigorous analysis. A common imagery is that a model is like a function with some parameters. One evaluates the function at a base set of parameter values, resets one of the parameters to another value (e.g., varying warning time), and recomputes. With a deterministic model, the results are reproducible. This procedure can be seen as a controlled scientific experiment.

In this image, agents "cause trouble." The typical complaint is that when agents are present, small changes of input can lead to substantially different outcomes for reasons that are difficult to understand, much less evaluate. This undercuts the desire for well-controlled, scientific, one-at-a-time study of how assumptions change things. To make things worse, some agents are stochastic.

My own view on this matter is deeply impatient. It seems to me that people have confused convenient with scientific. If in the real world minor changes of situation lead to adaptive behaviors resulting in substantially different paths being taken, so be it. The problem, ultimately, is that the real world - the system that we are attempting to represent - is not linear and its behavior is often not monotonic, at least at higher levels of observation. If this is so, then we should get used to it and think about what constitutes rigorous analysis in this context. Table 5 may be useful in doing so. The last column postulates something that is currently in short supply: agent-based models with good explanation capability.

The first requirement for rigor is that the cases be well defined. In my view, having agents doesn't change anything in this regard. Further, reproducibility is equally possible if the agents are deterministic. If they're not, then reproducibility should be achievable with enough samples.
Table 5: Contrasting Experiments with Models That Do and Do Not Have Agents

\begin{tabular}{|c|c|c|c|}
\hline Attribute & $\begin{array}{l}\text { Traditional } \\
\text { Models (no } \\
\text { agents) }\end{array}$ & $\begin{array}{c}\text { With } \\
\text { Agents }\end{array}$ & $\begin{array}{c}\text { With } \\
\text { Agents and } \\
\text { Explanation } \\
\text { Capability }\end{array}$ \\
\hline $\begin{array}{l}\text { Well defined } \\
\text { cases }\end{array}$ & Yes & Yes & Yes \\
\hline Reproducibility & Yes & Yes* & Yes* \\
\hline $\begin{array}{l}\text { Monotonic be- } \\
\text { haviors }\end{array}$ & Yes & No & No \\
\hline $\begin{array}{l}\text { Explainable } \\
\text { Behaviors }\end{array}$ & Yes & No & Yes* \\
\hline Well Behaved & Yes** & No & No \\
\hline
\end{tabular}

*But many current agents are stochastic, so that the concept of reproducibility is different than with deterministic models.

**Many legacy models are not as well behaved as myth would have it. See Speight (2003).

Monotonicity is another matter. Models with agents will often exhibit nonmonotonic behaviors. One generic cause of this is that a type of agent will reach a threshold and do something different thereafter, or will learn from experience and do something different. The whole purpose of the adaptations is to change the course of events (e.g., breaking off from a losing battle, or temporarily adopting swarm tactics to reduce one's attrition), so nonmonotonic trajectories are to be expected. If they are realistic, then so be it. In some cases, however, the models show unrealistic behaviors that may be described as chaotic. These are typically artifacts of imperfect decision rules, as noted by Andreas Tolk and Reiner Huber in the 1990s (see http : / / www . unibwmuenchen. de/campus / presse/hochschulkuri er/hsk06_99/tolk/tolk.html).

A key issue is explainability. Many agent-based models do rather mysterious things and that is not good for rigorous inquiry. The solution, then, would seem obvious: build in the explanation capability! I don't mean to be flippant, since doing so is a major challenge (Sanchez and Lucas 2002), but the conclusion seems evident.

As for well-behavedness, that is arguably in the eyes of the beholder. For someone accustomed to linear systems, then "well behaved" means one thing. For someone interested in the phase transitions of chemistry and physics, the discontinuous behaviors are marvelous, as is the discovery that sometimes one can "slip around" the discontinuities to obtain, temporarily, super-heated or super-cooled fluids. Similarly, social scientists-including military historians-have always been interested in how horseshoe nails, or discrete examples of brilliance or heroism, can have effects far beyond what might naively expect. Those who contemplate effects-based operations, including the potential "collapsing effects" of rapid-decisive operations, are very much interested in such matters, and very much 
aware that small things can make a difference. If pragmatically oriented, they will also identify regimes in which small differences will not have untoward effects.

Here again it is appropriate to mention the central role of exploratory analysis. In simple linear systems with fixed structures, it is possible to understand system behavior with a relatively small number of sampled observations: extrapolations and interpolations work well. That is not at all the case for complex adaptive systems, in which not only are there many nonlinearities, there are also changes in the very structure of the system. For example, small units may combine suddenly for a swarm operation, and then disperse. Or the character of a military campaign may change when a different leader takes the helm, or one of the combatant parties changes sides. When dealing with such complexity, analysis must invariably involve exploration. This exploration may involve more than merely checking end points.

\section{CHALLENGES FOR PRACTITIONERS OF MODELING AND SIMULATION}

Against this background of propositions, let me now suggest what the community of M\&S practitioners might regard as important challenges.

\subsection{Designing for Multiresolution, Multiperspective Models and Families}

The first challenge is systematically and consistently working to develop multiresolution, multiperspective modelsboth by building such features into individual models and by working out the relationships among models within what become model families. If those building models have this challenge in mind from the outset, much can be done with relatively little additional effort, whereas efforts to insert such features after the fact can be difficult.

In some instances, designing MRM models is straightforward. This occurs when the variables fall naturally into hierarchies. More often, this does not occur because "everything affects everything else," leading to interconnected graphs, rather than hierarchical structures. Experience, however, suggests that hierarchical structures are often good approximations, if merely one bothers to look for simplifications (Davis and Bigelow 1998).

The challenge of connecting pre-existing models is greater and often requires some reprogramming. Those who have been involved in building model federates are well aware of the issues and know that sensible connections can often be established, but not trivially.

The vision here is related to the larger ideal of model composability, which imagines libraries of models that can be assembled easily in plug-and-play fashion. That vision is seriously flawed for subtle reasons (Davis and Anderson 2004), but a weaker version certainly has merit. Existence proofs for weaker versions can be found in commercial games on one extreme, and in a few laboratories.

\subsubsection{The Special Problem of Low-Resolution Models}

Although I strongly support development of everimproving high-resolution models and simulations (e.g., Matsumura, et al. 2001), and regard this activity as crucial to the future of analysis, that seems to be less problematic in organizations than developing good low-resolution M\&S. When responsible officials understand the need to have low-resolution models for exploratory analysis, the common lament is "How do we obtain them?" From a theoretical perspective, the following suggest themselves:

1. Use a big model that was designed to facilitate parametric exploration, as was RAND's JICM model. Fairly modest reprogramming of some legacy models could produce comparable flexibility.

2. Build a new and relatively simple model from knowledge of phenomenology and the specific problem (something many of us have done with spreadsheet-level models of individual missions, such as airlifting forces or interdicting a moving army).

3. Generate a statistical metamodel by conducting experiments with a trusted high-resolution model (something I personally dislike, as discussed below).

4. Better than (3), generate a motivated metamodel by conducting experiments with a trusted highresolution model, but only after having specified a provisional analytical form based on phenomenology and allowing for correction terms if that form proves inaccurate (see below)

5. Build a data base of high-resolution runs and an interface mapping low-resolution questions into appropriately representative cases in the data base.

\subsubsection{Motivated Metamodeling}

Let me elaborate only on motivated metamodeling (Davis and Bigelow 2003), which is akin to what physical scientists have long done in analyzing experiments. The analytical form is postulated, based on a theory believed to be at least reasonably accurate, some room is left for correction factors and terms, and then the statistical machinery is applied. If the postulated form was good, then the statistical analysis establishes coefficients and the model is ready for explanation and drawing insights. If it is not so good, then the corrections are significant, suggesting the need for iteration.

This approach can be particularly important when describing systems or systems of systems that have multiple 
individually critical components. In that case, the natural analytical form may have a multiplicative form to enforce the point that failure of any critical component leads to failure overall. The effective of precision fires, for example, may depend on having excellent C4ISR and a delivery platform and a precision weapon. A failure of one cannot be compensated for by higher quality in the other. Such considerations should be a major element of capabilitiesbased planning (Davis 2002).

\subsection{Context-Dependent Aggregation and Disaggregation}

A second next challenge is building the methods and tools enabling analysts easily to construct context-dependent aggregations and disaggregations. Currently, aggregations are often accomplished by nothing more sophisticated than using an allegedly representative high-resolution case to evaluate the lower-resolution variable. An exchange ratio for a force-on-force engagement, for example, might be based on what some higher-resolution model predicts, assuming a particular configuration of attacker and defender consistent with the force ratio at issue. This is mathematically indefensible except in special cases. Conceptually, the nominal value of a low-resolution variable expressed as a parameter should be some kind of average over higherresolution scenarios and a higher resolution function. To use the same example, one should consider an entire distribution of attacker and defender configurations consistent with the low-resolution force ratio, and an entire distribution of assumptions about high-resolution details. What distribution should be used is highly context dependent. For example, if air-to-air combat, if one side has information superiority, then the engagements will be strongly skewed toward configurations favorable to that side. In particular, its aircraft will not be attacked from the rear. If one combines this with the orientation dependence of radar cross sections (including stealthy cross sections), the resulting exchange ratios can be dramatically different from those of a simple average over orientations.

What is wrong with just using a "representative" case? The answer is that there is no such thing. Depending on context, the best single case to use might be a conservative case in which the enemy gets the breaks, an optimistic case in which one's information superiority is credited with making the breaks, or a neutral no-one-has-advantage case. A classic example from the Cold War involved air-to-air combat. If the purpose was to appreciate the leverage of long-range missiles, then one might assume a configuration of long-range engagement of one friendly versus $n$ enemy aircraft. However, if one were concerned about cases in which rules of engagement might require visual detection, then n-on-n dog fights became more relevant, with drastically different results. Such issues should not have to be discovered only by clever analysts. Models and the tools that accompany them should make it easy to recognize the issues and work the different cases.

\subsection{Sophisticated Agents and Explanation Capability}

The last challenge area involves the issue of agents and explanation capability. The challenge for those doing agentbased modeling, I believe, is to move toward more sophisticated agents in more sophisticated simulations, and to build in explanation capabilities so that it is straightforward to follow the cause-effect chains.

This can be done, but it is not trivial. Indeed, it is one of the unsolved problems of artificial intelligence. However, much is possible if ambitions are limited. "Explanation" does not always have to be of the ultimate variety. It can be enough merely to follow chains of evaluations such as:

\author{
Because $\mathrm{X}$ was $\mathrm{X}^{\prime}$ \\ And $Y$ was $Y^{\prime}$ \\ And $Z$ was $Z^{\prime}$ \\ $\mathrm{Q}$ was evaluated as Q1
}

If the logic determining Q's value is tabular, then this explanation is straightforward and, in a sense, all there is. In other case, explanation would be much more complex, as in "because the horseshoe nail was lost, the horse was lost; because the horse was lost, ..." I have no generic solutions here, just the challenge. Until the challenge is met, there will continue to be resistance to agent-based models for analysis.

\section{CONCLUSIONS}

In conclusion, I have attempted in this short paper to lay out some provocative assertions and a set of corresponding challenges for the modeling and simulation community. The last decade's progress in modeling and simulation has been quite impressive and I would hope that the same will be said ten years hence.

\section{REFERENCES}

Bankes, Steven C. 1993. Exploratory modeling for policy analysis. Operations Research 41 (3).

Davis, Paul K., J. Kulick, and M. Egner. 2005. Implications of modern decision science for military decision support. Santa Monica, CA: RAND MR-360-AF.

Davis, Paul K. and James H. Bigelow. 1998. Experiments in multiresolution modeling. Santa Monica, CA: RAND MR-1004-OSD.

Davis, Paul K. and James H. Bigelow. 2002. Motivated metamodeling: A synthesis of cause-effect modeling and statistical methods. Santa Monica, CA: RAND. 
Davis, Paul K. and Robert H. Anderson. 2004. Improving the composability of DoD models and simulations. Journal of Defense Modeling and Simulation 1 (1).

Davis, Paul K., 2002. Analytic architecture for capabilities-based planning, mission-system analysis, and transformation. Santa Monica, CA: RAND.

Davis, Paul K. (ed.). 1993. New challenges in defense planning: Rethinking how much is enough. Santa Monica, CA: RAND.

Davis, Paul K., Steven C. Bankes, and James P. Kahan. 1986. A new methodology for modeling national command level decisionmaking in modeling and simulation. Santa Monica, CA: RAND R-3290-NA.

Dreyer, Paul and Paul K. Davis. 2005. The portfolio analysis tool for ballistic missile defense (PAT-MD). Santa Monica, CA: RAND,

Epstein, Joshua and Robert Axtell. 1996. Growing artificial societies. Washington, D.C: Brookings.

Fox, Daniel. 2003. Using exploratory modeling. In New Challenges, New Tools for Defense Decision Making, ed. Stuart Johnson, Martin Libicki, and Greg Treverton. Santa Monica, CA: RAND.

Franklin, Stan and Art Graesser. 1996. Is it an agent, or just a program?: A taxonomy for autonomous agents. Available online via http://www.msci.memphis.edu/ frankli n/AgentProg.html.

Hill, Raymond, Lance E. Champagne, and Joseph C. Price. 2004. Using agent-based simulation and game theory to examine the WW II Bay of Biscay u-boat campaign. Journal of Defense Modeling and Simulation 1 (2): 99-109.

Horne, G. and S. Johnson (eds.). 2002. Maneuver warfare science. Quantico, VA: USMC Project Albert.

Ilachinski, Andrew. 2000. Irreducible Semi-autonomous adaptive combat (ISAAC): An artificial life approach to land combat. Military Operations Research Journal 5 (3): 29-46. See also Ilachinski's web site, best found with a search engine.

Lauren, Michael, Roger T. Stephen, and Mark A. Anderson. 2002. MANA: Map aware non-uniform automata version 2.0 user's manual. Davenport Naval Base, Auckland, New Zealand: New Zealand Defence Technology Agency.

Lempert, Robert J., Steven W. Popper, and Steven C. Bankes. 2003. Shaping the next hundred years: New methods for quantitative long-term policy analysis. Santa Monica, CA: RAND.

Lucas, Thomas, The stochastic versus deterministic argument for combat simulations: Tales of when the average won't do. Military Operations Research Journal 5 (3): 9-28.

Matsumura, John, Randall Steeb, et al. 2001. Lighting over water: Sharpening america's light forces for rapid missions. Santa Monica, CA: RAND.
McEver, Jimmie, Paul K. Davis, and James A. Bigelow. 2000. EXHALT: an interdiction model for the halt phase of armored invasions. Santa Monica, CA: RAND.

National Research Council. 2005. Naval analytical capabilities: Improving capabilities-based planning. Washington, D.C.: National Academy Press.

National Research Council. 1997. Modeling and simulation. Technology for the United States Navy and Marine Corps. 2000-2035 9. Washington, D.C.: National Academy Press.

Sanchez, Susan M. and Thomas W. Lucas. 2002. Exploring the world of agent-based simulations: Simple models, complex algorithms. In Proceedings of the 2002 Winter Simulation Conference 116-126.

Schwabe, William. 1992. Analytic war plans: Adaptive force-employement logic in the RAND strategy assessment system (RSAS). Santa Monica, CA: RAND R-3051.

Shlapak, David. 1988. Green agent user's guide. Santa Monica, CA: RAND N-2812-NA.

Speight, Richard. 2003 'Structural variance' or 'nonmonotonicity effects' in combat models: A review. Military Operations Research Journal 8 (1): 5-22.

Zinn, Andrew W. 2004. The use of integrated architectures to support agent based simulation: An initial investigation. Master's Thesis, Air force Institute of Technology. Wright-Patterson Air Force Base, Ohio.

\section{AUTHOR BIOGRAPHY}

PAUL K. DAVIS is a senior scientist and Research Leader at the RAND Corporation, and Professor of Policy Analysis in the Pardee RAND Graduate School. Dr. Davis' research areas include defense planning, strategic planning more generally, advanced methods of modeling and analysis, decision making theory, and counterterrorism theory. He has published pioneering papers on the theory and practice of capabilities-based planning, multi resolution modeling, and exploratory analysis. His e-mail and web addreesses are pdaviserand.org and www. rand.org/personal/pdavis, respectively. The latter has online versions of most of the cited papers. 